\title{
Characteristics of babies referred for Retinopathy of prematurity screening and management to a tertiary eye hospital of Bangladesh, a database analysis
}

Jean Claude Niyonzima ( $\square$ claudeniyonzima@gmail.com )

Kibuye hospital https://orcid.org/0000-0002-7329-5343

Nazmun Nahar

Ispahani Islamia Eye Institute and Hospital

Mahjabeen Chowdhury

Ispahani Islamia Eye Institute and Hospital

Sanjoy Kumar Das

Ispahani Islamia Eye Institute and Hospital

Mostafizur Rahman

Ispahani Islamia Eye Institute and hospital

Research article

Keywords: Retinopathy of prematurity, screening, treatment options, Referrals

Posted Date: October 15th, 2019

DOl: https://doi.org/10.21203/rs.2.16050/v1

License: (c) (i) This work is licensed under a Creative Commons Attribution 4.0 International License.

Read Full License 


\section{Abstract}

Background: Ispahani Islamia Eye Institute and Hospital (IIEIH) is a leading ROP screening center in Bangladesh. The study had an aim to analyze the characteristics of referred babies and identify possible bottlenecks.

Methods : Electronic records of babies referred to IIEIH for a period of three years (2016-2918) were analyzed retrospectively. All the babies registered in the electronic file were screened by any of the three consultants with keen interest in ROP. Variables of interest were ROP stage, gestational age, birth weight, time to screening, referring institution and treatment modalities (laser, Anti-VEGF, retina surgery or combination). Data were exported to SPSS version 23 for Mac for descriptive and correlation analysis. Pvalue less than 0.05 was considered statistically significant.

Results: 887 babies with ROP stage 1 or above were registered, a large majority were referred by private institutions (75\%), $60 \%$ of babies were moderate pre-terms according to WHO classification, the mean birth weight was $1563 \pm 397.1$ grams. ROP was largely stage $2(37 \%)$ and $61 \%$ of babies had at least one treatment modality. The younger the gestational age and the lower the birth weight, the higher the risk of presenting with ROP with advanced stage.

Conclusion : The majority of babies with ROP came from private institutions and more than half of them needed at least one treatment modality. We recommend a large study to analyze the incidence and availability of ROP services in public hospitals.

Key words : Retinopathy of prematurity, screening, treatment options, Referrals

\section{Background}

In 2014, Bangladesh ranked fourth in the top ten countries with the highest incidence of pre-terms population behind India, China and Nigeria respectively first, second and third. The same report showed an estimate of $19 \%$ of 3152549 livebirths were pre-terms, representing $4 \%$ of the global population of pre-terms. [1]

ROP screening in Dhaka started in 2010, IIEIH and National Institute of Ophthalmology (NIO) were the only screening centers by then. They offered limited services for a period of 2 years. In 2013, Orbis International joined the centers and supported the human resources empowerment and raising awareness on ROP. [2]

In a local press release, the ROP team at Ispahani Islamia Eye Institute and Hospital (IIEIH) in partnership with Orbis international warned there was rising incidence of blindness secondary to ROP thought to be linked to low rate of detection of ROP in the neonatal intensive care units (NICU) of the country or a late screening of babies who are already at advanced stage of the disease. [3] 
Besides these concerns, there was an international concern over rising incidence of ROP in the developing countries referred to as "the third epidemic" of blindness directly linked to ROP.[4]

It is now known that low gestational age, low birth weight, exposure to high concentration of oxygen and neonatal sepsis are high risk factors for ROP. WHO categorizes prematurity in 3 stages: extreme preterm $<28$ weeks, very preterm 28 to less than 32 weeks and late preterm between 32 and 37 weeks. [5]

Some efforts have been deployed to improve the ROP screening in Dhaka and IIEIH is one leading referral center for ROP screening. At least 20 NICUs in the town of Dhaka are referring babies to IIEIH who either meet the objective criteria (gestational age $<33$ weeks or birth weight $<2000$ grams) or assumed to be at higher risk at the discretion of the neonatologists. Some babies may come from other centers, these ones are usually seen lately and may already have an advanced disease.

In 2017, a study presented an overview of the screening program at IIEIH with a focus on the pattern of ROP in the screened population. The major conclusion lines highlighted the significant public concern brought in by ROP morbidity and the need for a stronger government response. [2]

This study has an objective to analyze the characteristics of babies referred for ROP screening and help to get the clear picture of the level of ROP services delivery among the surrounding health facilities.

\section{Methods}

This is a cross - sectional study conducted at IIEIH, an urban tertiary eye hospital of Dhaka, Bangladesh. The data were retrieved in the ROP screening electronic database covering the period from January 2016. The study period covered January 2016 till December 2018. The database is an excel folder that stores patients' medical records numbers, gestational age, birth weight, ROP stage, time to screening, referring institution (private, public, not for profit or self-referrals) and treatment modalities (laser, Anti-VEGF, retina surgery or combination).

Data were broken down monthly. Since the database was specifically designed for ROP, all the stored data were included in the study. There were no exclusion criteria.

The investigator did not get access to the whole database but was granted a copy of the data for the specific period of the study by the Head of the Department.

To process the data, the investigator checked the datasheet for completeness before they were exported to SPSS version 23 for Mac for descriptive and correlation analysis. A one sample T- test was used to test for correlation. Results were presented by means of tables, pie-charts, bar charts. P-value less than 0.05 was considered statistically significant.

The study was approved by Ispahani Islamia Eye Institute and Hospital Ethical Research Committee (IIEIH-ERC) and no patients consent forms were needed since the research used a database and did not involve any human or photography. 


\section{Results}

- ROP in numbers

We retrieved 2540 babies screened for the three years period in the database among which 887 had ROP of any stage. The ROP incidence was $34.9 \%$. Demographic and some clinical data were not available yet in the database. The summary of numbers of babies screened and treated are presented in table 1.

More than half $(53 \%)$ of the screened babies were eligible for at least one treatment modality. Laser is the most commonly prescribed and performed procedure. Cumulatively, 382 babies underwent laser photocoagulation over the 3 years period. Trends analysis for the same period shows there is a sharp increase in use of anti-VEGF(from 6 cases in 2016, 49 in 2017 to 68 in 2018) and a shy decrease in numbers of babies who need vitreoretinal surgeries (from 22 surgeries in 2016, 19 in 2017 to 16 in 2018). Some babies required a combination of 2 or 3 treatment options.

- Gestational age

The gestational age is presented in the figure 1. Five hundred twenty-eight babies $(60 \%)$ were moderate or late preterm according to WHO classification. Of note, 216 babies were older than 33 weeks and 14 babies (2\%) did not fit in any WHO category of prematurity although diagnosed to have various stages of ROP. The mean gestational age was 31.92 .3 weeks, with a range of 23 to 40 weeks.

- Birth weight

The birth weight mean was 1563397 grams, with a range of 600 to 3700 grams. The birth weight subcategories commonly used in ROP studies are summarized in figure 2

- ROP staging

The stage 2 ROP was the most prevalent among babies seen. Stages 3 and 1 have almost a similar prevalence. Of note, the aggressive posterior ROP (APROP) prevalence was as high as $10.5 \%$. details are shown in Fig.3

- Chronological age and time to screening

Barely half of the babies (55.3\%) were screened within one month of their chronological age, the mean time to screening was 1.71 .19 months, with a range of 1 to 10 months. More details are presented in figure 4 .

- Origin of referrals

The majority of babies are referred by private practitioners (75.4\%). Public hospitals referred $18.4 \%$. Note that almost $3 \%$ of babies came directly from the community(self-referred) 
- Correlation analysis

There is a negative correlation between the gestational age, birth weight and ROP, the lower the parameter, the higher the risk for severe ROP stage. Conversely, the babies who delayed coming to the hospital were likely to have a higher ROP stage. Values are displayed in table 2.

- Subset analysis

There were 14 babies older than 37 weeks of gestational age in the database. Four of these babies were treated. Three had low birth weight of 1300 grams each, the fourth was seen later after 2 months and the weight was already 3000 grams. One baby had a stage 5 ROP, no surgical intervention was possible.

\section{Discussion}

IIEIH screened more than 800 babies yearly and therefore the institute can be regarded as one of the most important ROP centers in the world. This is an important dataset for ROP screening compared to the numbers seen in the literature. [6-10]

IIEH ROP experience shows how ROP screening and management services can be scaled up in a given hospital; from 50 ROP cases screened in year 2012 to a yearly average of 296 cases in the last 3 years is a giant step made forward.[2]

The incidence of ROP among the referrals was $34.9 \%$. Incidences reported in the literature vary often and depend on the screening guidelines of each country. In this study, although the screening guidelines targeted preterm babies younger than 33 weeks of gestational age or babies with birth weight lower than 1500 grams, there was a big number of babies older than that GA. Elsewhere, reported incidence was calculated at 32 weeks of GA and there is clear difference between developed and developing countries whereby ROP incidence appears to be lower in the former and higher in the latter: France (22.3\%), Sweden(25.5\%), United kingdom (19.2\%), India (37.2\%), Kenya(40\%), Saudi Arabia(41\%), Iran (47.3\%),Turkey(50.9\%) and Istanbul (52.7\%). [6,11-16]

Among the babies screened to have any ROP stage, $53 \%$ needed at least one treatment modality. As reported and supported by other researchers in this field, photocoagulation laser remains the most common treatment modality for ROP and was performed in 389 cases alone or combined with other treatment options. Trends analysis for the 3 years period shows there is a shy but steady increase in use of anti-VEGF(from 6 cases in 2016, 49 in 2017 to 68 in 2018) and a decrease in numbers of babies who were admitted for vitreoretinal surgeries (from 22 surgeries in 2016, 19 in 2017 to 16 in 2018). However, this trend should be analyzed with caution as it does not necessarily mean there is a decrease in the ROP stage $4 \& 5$. For instance, in this study, there were 111 babies who presented with ROP stage 4 or 5 but only 80 were selected for surgery.

The mean gestational age in this study is obviously higher than those usually reported elsewhere, and some 14 babies were not preterm as they exceeded 37 weeks. Some of the babies had low birth weight or 
had other risk factors including but not limited to admission in a NICU for sepsis or anemia necessitating transfusion. Nine babies did not need any treatment, three had 1300 grams of birth weight and were treated by laser and one who reported lately after 8 weeks in NICU needed retinal detachment surgery. Other researchers have postulated ROP incidence was found to be more associated with low birth weight rather than gestational age. [17]

Although ROP in big babies has been reported in India, the authors still put a caveat on the accuracy of the reported gestational age and recommended emphasis on younger preterm rather than big babies so not to waste man-hours.[11,18]

The same scenario is observed with the birth weight analysis that shows a mean of 1563397 grams, some babies weighing even above 3000 grams. This was comparable to the findings of Akçakaya et al in their study on ROP screening in a tertiary eye hospital in Istanbul where the birth weight mean was 1,549.4 \pm 512.9 grams. [19] Al-Amro et al in Saudi Arabiahad a completely different scenario where ROP was only diagnosed in babies aged less than 32 weeks and who had a birth weight less than 1250 grams. [9] This may be due to the fact that IIEIH cut-off for screening is 33 not 32 weeks and is a referral center as opposed to other research centers that report data obtained from their own hospitals NICU. Moreover, some babies were not referred by a health professional, which means they decided to consult when parents noted obvious symptoms like poor or no fixation or leukocoria. A subset analysis of 'selfreferred' group showed 7 babies (26\%) were classified ROP stage 5 of whom only one baby was admitted for surgery. This is a clue that these babies come very late to the hospital.

The time (postnatal age) to screening is also following the same trend as the gestational age and birth weight as it is obviously longer than what we would expect. It is worth-noting that $9 \%$ of babies came after 3 to 10 months of chronological age. Delayed screening is a matter of concern as it is an important prognostic factor for the successful management of ROP. Many clinicians and researchers insist there is a short window for screening between symptoms appearance and complications occurrence. However, this has been a debate and may change from population to population. [9]

The socioeconomic status of the families was not available in our database and such a valuable information may shed more light on the issue of delayed screening.

Our finding on ROP staging is in agreement with other researchers' reports as stage 2 was the most prevalent in our case series. Aggressive posterior ROP was $10.5 \%$ of the cases. Other authors reported the similar incidence in India (13.2\%). [20]

The classification in zones was not available in the database and should be included in the future.

The referring institutions were private in the majority of cases. We could not ascertain whether the babies were necessarily born in the referring hospitals or whether they consulted in a private institution later after birth. In the first hypothesis, two scenarios are possible; either ROP screening is effectively happening in 
the public hospitals and there is no need to refer or parents of babies born in public hospitals do not get to know about ROP screening. The former is less likely based on the literature. $[2,3]$

In the second hypothesis, it would mean many parents trust private pediatricians and still visit them even after the babies were born in public hospitals. Whichever hypothesis is considered, public hospitals need their mother and child health strategy reinforced to bridge the gaps noted in ROP screening and timely management.

\section{Conclusions}

IIEIH is an important ROP screening center given the numbers seen yearly and has achieved a great deal in services scaling up over the last few years. The database is an excellent tool that helps monitoring the progress, however socio-economic, ROP zones, "plus disease" occurrence data are yet to be included. Babies with ROP risk factors are referred late and some have advanced disease that require vitreo-retinal surgeries. The public hospitals need to strengthen their mother and child health strategy to capture the babies at risk of ROP on time.

\section{Declarations}

Ethics approval and consent to participate: This is a database analysis; however, a consent was taken from babies' parents before screening and treatment and agreed their data to be used for research purpose. The study was approved by IIEIH -ERC

Consent for publication: Study approved by the relevant authority (IIEIH-ERC)

Competing interests: None of the authors has competing interest to declare

\section{Funding: None}

\section{Authors' contributions:}

- Nazmun Nahar designed the study concept and directed each step of the study, screened and treated babies with ROP

- Jean Claude Niyonzima was in charge of writing the draft subsequently ratified by the rest of the team

- Mahjabeen Chowdhury, Sanjoy Das Kumar, Mostafzur Rahman, were responsible for screening and treating babies with ROP, contributed to the study development, discussed the results and approved the manuscript before submission.

Acknowledgements: all the data were easily gathered thanks to Selina Akthar in charge of the ROP database. 
Availability of data and materials: The hospital owns a database for ROP screening and management and has been regularly updated and shared with the public through diverse canals. The dataset for this article can be accessed on a reasonable request basis.

\section{Abbreviations}

ROP: Retinopathy of prematurity

NICU: new-born intensive care unit

GA: gestational age

IIEIH: Ispahani Islamia Eye Institute and Hospital

ERC: Ethical Research Committee

\section{References}

1 Chawanpaiboon S, Vogel JP, Moller AB, et al. Global, regional, and national estimates of levels of preterm birth in 2014: a systematic review and modelling analysis. Lancet Glob Heal 2019; 7:e37-46. doi:10.1016/S2214-109X(18)30451-0

2 Nahar N, Badmus SA, Das SK, et al. Retinopathy of prematurity in Bangladesh: an overview. Community eye Heal 2018;31:S25-6.

3 Banglanews24. ROP-caused blindness increasing. 2014-11-10.

2014.https://m.banglanews24.com/index.php/health/article/31191/ROP-caused-blindness-increasing

4 Gilbert, C. Alistair Fielder, Luz Gordillo, Graham Quinn, Renato Semiglia PV. Characteristics of Infants With Severe Retinopathy of Prematurity in Countries With Low, Moderate, and High Levels of Development: Implications for Screening Programs. Pediatrics 2005;115:e518-25. doi:10.1542/peds.2004-1180

5 WHO. Preterm birth. World Heal. Organ. 2018;:1-5. doi:10.1097/00003081-198409000-00003

6 Onyango 0 , Sitati S, Amolo L, et al. Retinopathy of prematurity in Kenya: Prevalence and risk factors in a hospital with advanced neonatal care. Pan Afr Med J 2018;29:1-7.

doi:10.11604/pamj.2018.29.152.14046

7 Padhi TR, Jain L, Behera UC, et al. Retinopathy of Prematurity Profile and Trend Over the Years: Experience From a Two tier City in Eastern India. Indian Pediatr 2016;53:S76-9.

8 Hashmi FK, Chaudhry TA, Ahmad K. An evaluation of referral system for retinopathy of prematurity in leading health centers across Karachi, Pakistan. J Pak Med Assoc 2010;60:840-4. 
9 Al-Amro SA, Al-Kharfi TM, Thabit AA, et al. Retinopathy of prematurity at a University Hospital in Riyadh, Saudi Arabia. Saudi Med J 2003;24:720-4.

10 Abrishami M, Maemori G-A, Boskabadi H, et al. Incidence and Risk Factors of Retinopathy of Prematurity in Mashhad, Northeast Iran. Iran Red Crescent Med J 2013;15:229-33. doi:10.5812/ircmj.4513

11 Akman I, Demirel U, Yenice Ö, et al. Screening criteria for retinopathy of prematurity in developing countries. Eur J Ophthalmol 2010;20:931-7. doi:10.1093/tropej/fml071

12 Ebrahim M, Ahmad RS, Mohammad M. Incidence and risk factors of retinopathy of prematurity in Babol, North of Iran. Ophthalmic Epidemio/ 2010;17:166-70. doi:10.3109/09286581003734860

13 Beby F, Burillon C, Putet G, et al. Rétinopathie du prématuré: résultats de l'examen du fond d'oeil chez 94 enfants à risque. J Fr Ophtalmo/ 2004; 1080:337 YP-439. doi:http://dx.doi.org/JFO-04-2004-27-40181-5512-101019-ART1

14 Anudeep K, Srikanth K, Sindal M, et al. Study of Incidence Risk Factors and Treatment Outcomes in Retinopathy of Prematurity in a Tertiary Care Center. J Ophthalmic Sci Res / 2019;:24-6. doi:10.4103/tjosr.tjosr

15 Larsson E, Holmström G. Screening for retinopathy of prematurity: evaluation and modification of guidelines. Br J Dermatol 2002;86:1399-402.

16 Mathew MRK, Fern Al, Hill R. Retinopathy of prematurity: Are we screening too many babies? Eye 2002;16:538-42. doi:10.1038/sj.eye.6700031

17 Araz-Ersan B, Kir N, Akarcay K, et al. Epidemiological analysis of retinopathy of prematurity in a referral centre in Turkey. Br J Ophthalmol 2013;97:15-7. doi:10.1136/bjophthalmol-2011-301411

18 Gilbert C, et al. Severe retinopathy of prematurity in big babies in India: History repeating itself? Indian J Pediatr 2009;76:801-4. doi:10.1007/s12098-009-0175-1

19 Akçakaya AA, Yaylali SA, Erbil HH, et al. Screening for Retinopathy of Prematurity in a Tertiary Hospital in Istanbul: Incidence and Risk Factors. J Pediatr Ophthalmol Strabismus 2012;49.21-5. doi:10.3928/01913913-20110208-01

20 Hungi B, Vinekar A, Datti N, et al. Retinopathy of prematurity in a rural neonatal intensive care unit in south India-A prospective study. Indian J Pediatr 2012;79:911-5. doi:10.1007/s12098-012-0707-y

\section{Tables}

Table 1: Incidence of ROP and treatment needs 


\begin{tabular}{|l|l|l|l|l|}
\hline & 2016 & 2017 & 2018 & Total (\%) \\
\hline Screened babies & 953 & 778 & 809 & $2540(100 \%)$ \\
\hline ROP(Incidence) & $246(25.8 \%)$ & $292(37.5 \%)$ & $349(43.1 \%)$ & $887(34.9 \%)$ \\
\hline No treatment & 121 & 137 & 159 & $417(47)$ \\
\hline Laser treatment & 102 & 89 & 118 & $309(34.8)$ \\
\hline Anti-VEGF injections & 1 & 26 & 22 & $49(5.5)$ \\
\hline VR surgeries & 18 & 13 & 11 & $32(3.6)$ \\
\hline Laser +Anti-VEGF & 3 & 21 & 44 & $68(7.7)$ \\
\hline Laser +VR surgery & 0 & 4 & 3 & $7(0.8 \%)$ \\
\hline Laser +Anti-VEGF+VR surgery & 1 & 2 & 2 & $5(0.6 \%)$ \\
\hline
\end{tabular}

Table 2: correlation analysis

\begin{tabular}{|l|l|l|}
\hline & Pearson value & P-Value \\
\hline Gestational age & $-0.221^{*}$ & $<0.001$ \\
\hline Birth weight & $-0.122^{*}$ & $<0.001$ \\
\hline Time to screening & $0.219^{*}$ & $<0.001$ \\
\hline
\end{tabular}

*Correlation is significant at 0.01 level(2-tailed)

\section{Figures}




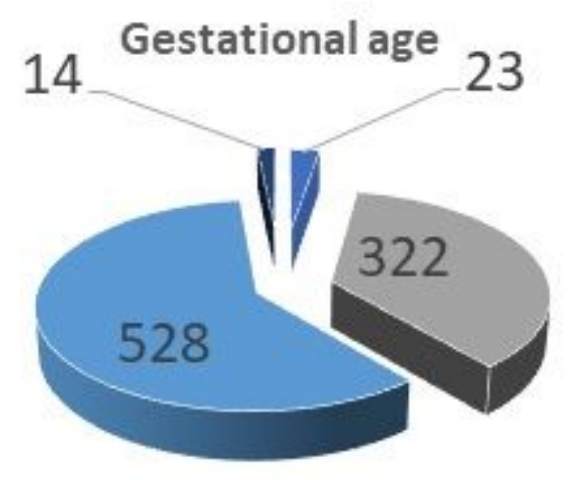

- $<28 \quad=28-31 \quad=32-37 \quad$ - older

\section{Figure 1}

Gestational age according to WHO categories

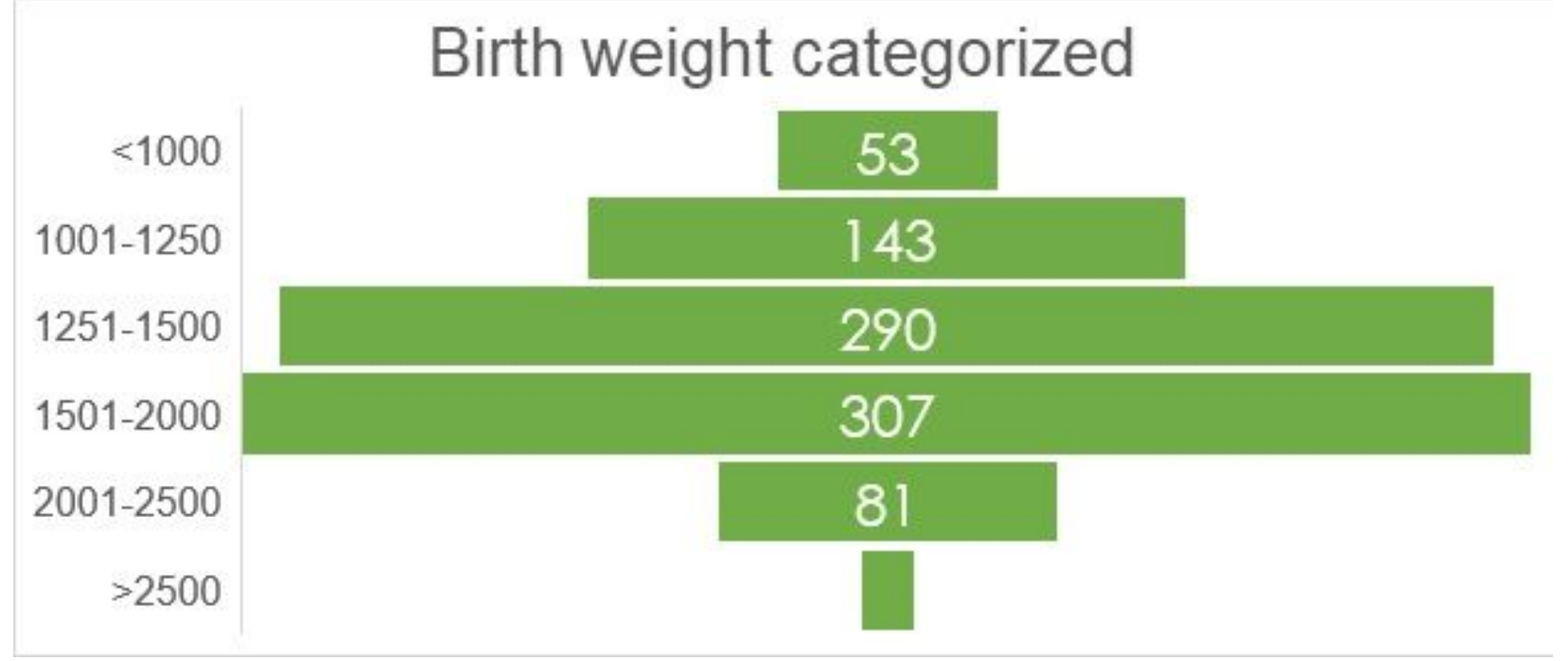

\section{Figure 2}

birth weight subcategories 


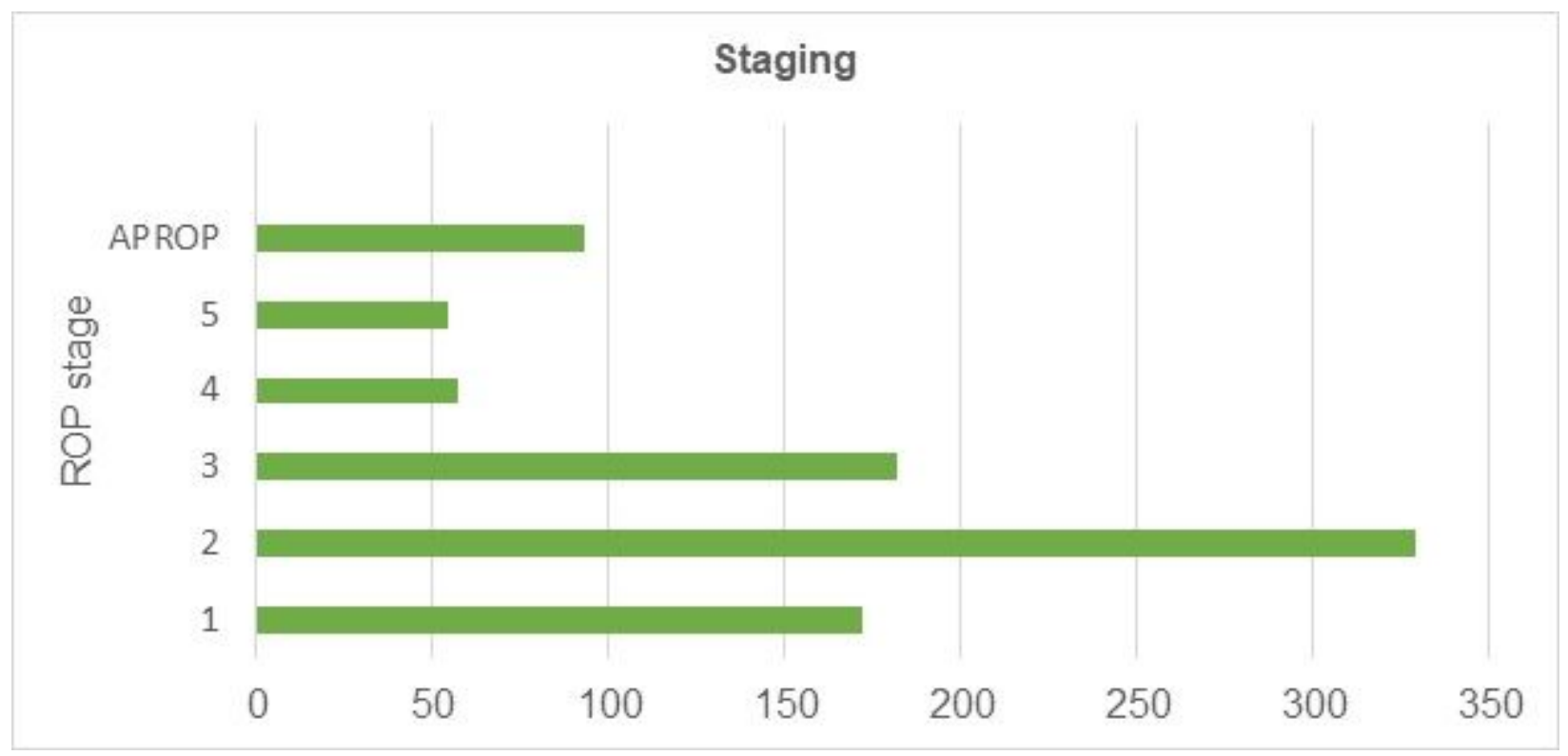

Figure 3

ROP staging

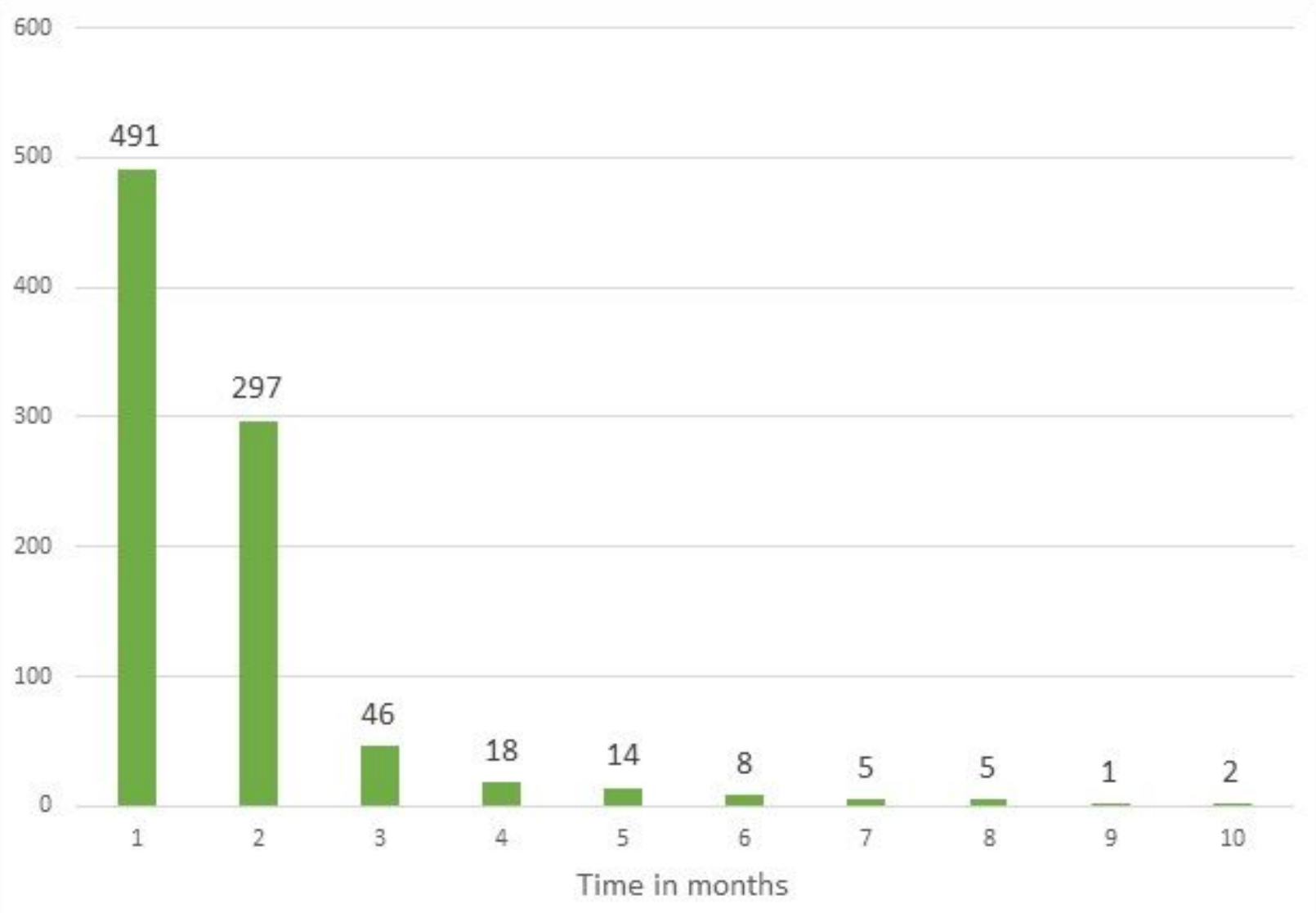

Figure 4

chronological age at time of screening 


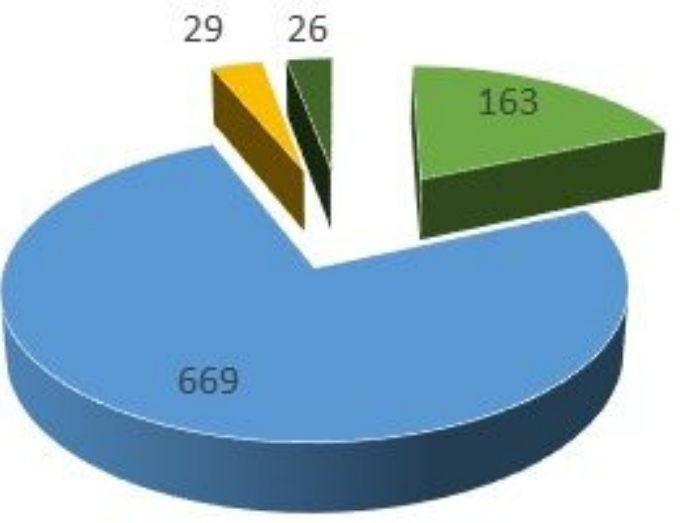

- Public hospitals

- Private Hospital

- NGO Hospitals

- Self-referred

Figure 5

origin of referrals 